UWS Academic Portal

\title{
Effect of temperature variation on the corrosion behaviour and semiconducting properties of the passive film formed on chromium oxide coatings exposed to saline solution
}

Oje, A.M.; Ogwu, A.A.; Rahman, S. Ur; Oje, Alex I.; Tsendzughul, Nathaniel

Published in:

Corrosion Science

DOI:

10.1016/j.corsci.2019.04.004

Published: 01/07/2019

Document Version

Peer reviewed version

Link to publication on the UWS Academic Portal

Citation for published version (APA):

Oje, A. M., Ogwu, A. A., Rahman, S. U., Oje, A. I., \& Tsendzughul, N. (2019). Effect of temperature variation on the corrosion behaviour and semiconducting properties of the passive film formed on chromium oxide coatings exposed to saline solution. Corrosion Science, 154, 28-35. https://doi.org/10.1016/j.corsci.2019.04.004

\section{General rights}

Copyright and moral rights for the publications made accessible in the UWS Academic Portal are retained by the authors and/or other copyright owners and it is a condition of accessing publications that users recognise and abide by the legal requirements associated with these rights. 
Effect of temperature variation on the corrosion behaviour and semiconducting properties of the passive film formed on chromium oxide coatings exposed to saline solution

A.M. Oje*, A.A. Ogwu ${ }^{1}$, S.Ur Rahman, A.I. Oje, Nathaniel Tsendzughul School of Engineering and Computing

University of the West of Scotland,

High Street,

Paisley PA1 2BE, Scotland, U.K.

1) East Kazakhstan State Technical University, Ust-Kamenogorsk, Republic of Kazakhstan *Corresponding author

E-mail: Michael.oje@uws.ac.uk 


\begin{abstract}
The corrosion behaviour of chromium oxide coatings and semiconducting properties of the passive film formed on the surface of the coated samples when exposed to saline solution at a temperature range $25^{\circ} \mathrm{C}$ to $65^{\circ} \mathrm{C}$ was investigated. The cyclic polarisation results revealed that the coatings tested at an electrolyte temperature range $25^{\circ} \mathrm{C}$ to $35^{\circ} \mathrm{C}$ possess superior resistance to pitting corrosion when compared to coatings tested at higher temperatures. Our MottSchottky analysis suggests that this variation in corrosion resistance can be linked to the increase in the amount of the defect density present in the films and enhanced diffusion at higher temperatures.
\end{abstract}

Keywords: Chromium oxide coatings, corrosion, semiconducting properties, elevated temperatures, saline solution 


\section{Introduction}

Materials such as stainless steel, CoCrMo, titanium as well as most coating materials form either a protective or non-protective oxide layer on their surfaces when exposed to certain atmospheric conditions or in a specific aqueous solution such as saline and physiological solutions [1,2]. The protective oxide layer can act as a barrier between the coating and the corrosive environment and limit the ease of diffusion of aggressive ions to the substrate, leading to a significant reduction in the corrosion rate of the material[1,3]. For instance, it has been found that stainless steel and CoCrMo forms oxides or hydroxide layer, e.g. $\mathrm{Cr}_{2} \mathrm{O}_{3}$ on their surfaces which assists in sustaining their improved corrosion resistance against degradation $[2,4]$. Nowadays, transition metal oxides and nitrides coatings are applied to the above substrate materials to improve their mechanical, corrosion and tribological properties further to permit their usage in various engineering applications. In application area such as orthopaedics implant applications, such oxide layers not only enhance corrosion resistance of the coating material but also help to suppress the release of carcinogenic metallic ions from the substrate material [4,5]. It has been reported that during the passivation process (oxide layer formation) or re-passivation process, the corrosion rate of the coating or material possessing the oxide layer reduces and the rate of ion release is retarded [4,5]. Hence, the durability and integrity of such an oxide layer are necessary for the optimum performance of the coating materials for corrosion resistance applications. Different parameters such as oxygen flow rate used during the coating preparation, electrolyte temperature, $\mathrm{pH}$ values, exposure time, and electrolyte concentration can affect the semiconducting properties of the passive film and invariably the corrosion behaviour of the material.

Li et al. [3] evaluated the semiconducting properties of the passive layer formed on nickelbased alloy exposed to bicarbonate/carbonate buffer solution. They found that the donor/acceptor densities in the oxide layer on the nickel-based alloy decreased with an increase in the potential, $\mathrm{pH}$ value and exposure time which enhanced the corrosion protection of the substrate material. In a similar investigation, Kong et al.[6] examined the semiconducting properties of the passive layer formed on chromium in both $0.5 \mathrm{MH}_{2} \mathrm{SO}_{4}$ and borate buffer solutions. The researchers reported an increase in the defect density in the passive film formed on the sample due to prolong passivation time and lowering of film passivation potential leading to an increase in corrosion rate of the material.

Chromium oxide coatings have been studied as a possible protective coating material for stainless steel/other substrates and were found to enhance their corrosion and wear properties 
[7-13]. Previously studies conducted on chromium oxide coatings in various solutions $[10,12,14]$ have shown that the oxide layer formed on the coating possesses a p-type semiconductivity with varying level of defect density depending on the coating preparation parameters and electrolyte condition. For chromium oxide coatings prepared by reactive magnetron sputtering and tested in Ringer's solution at $37^{\circ} \mathrm{C}$, it has been observed that a decrease in the level of oxygen doping in the chromium oxide coatings resulted in a decrease in the defect density and a corresponding improvement in the corrosion resistance of the coating [12]. Although an increase in the electrolyte temperature is envisaged to accelerate the corrosion rate of chromium oxide coatings tested in saline solution, no study in the literature has investigated this effect alongside any possible correlation between the semiconducting properties of the oxide layers and the corrosion behaviour of the coatings at a range of temperatures. The understanding of the interactions between the electrolyte and the oxide layer formed on the coatings in relation to the operating temperatures is key in developing stable protective coating material for high-temperature applications.

In this paper, we report our investigation into the influence of temperature variation on the corrosion behaviour of chromium oxide coatings and semiconducting properties of the passive oxide layer formed on the samples when exposed to saline solution. The semiconducting properties of the oxide layer were investigated by Mott-Schottky analysis while the electrochemical behaviour of the coatings was investigated using the electrochemical impedance spectroscopy (EIS), and cyclic polarisations techniques.

\section{Experimental Methods}

\subsection{Thin Film Deposition}

The chromium oxide thin films deposition was performed with a Cryo-pumped vacuum chamber RF magnetron-sputtering unit using the deposition conditions shown in Table 1. Solid chromium (99.99\%) target was used as the starting material with high purity argon and oxygen as sputtering and reactive gases, respectively. The substrate materials used were 304 medical grade stainless steel and glass slides substrates. The substrates for corrosion tests were cut into square shape of $80 \times 80 \mathrm{~mm}$ pieces, ground and metallographically polished. The substrates were cleaned ultrasonically with an iso-propanol solution and then washed with de-ionised water. The deposition chamber was evacuated to a pressure of about $8 \mu$ Torr before deposition, and the depositions were carried out under the vacuum condition. Pre-sputtering was also performed before starting the main deposition to clean the target from any contamination. 
Chromium oxide thin films of equal thicknesses $(\sim 220 \mathrm{~nm})$ were deposited on all the stainless steel substrates for the corrosion test as this is necessary for the comparison of the electrochemical properties of the coatings at different electrolyte temperature conditions. The film's thickness was controlled by keeping the deposition parameters shown in Table 1 constant during the preparation of each of the samples. The thickness and uniformity of the coatings were further controlled by ensuring that the substrate/sample holder was in gradual rotating speed of $5 \mathrm{rpm}$ throughout the deposition process.

Table 1: Deposition parameters for the prepared chromium oxide coatings.

\begin{tabular}{|c|l|}
\hline Forward power & $500 \mathrm{~W}$ \\
\hline Oxygen flow rates & $10 \mathrm{sccm}$ \\
\hline Argon flow rate & $60 \mathrm{sccm}$ \\
\hline Deposition time & 120 minutes \\
\hline Substrate temperature & ambient temperature \\
\hline Reflected power & $<6 \mathrm{~W}$ \\
\hline
\end{tabular}

\subsection{Material Characterisation}

The morphology of the coatings was examined with the scanning electron microscope (Hitachi S-4100 model) and elemental composition of the coatings was determined using the EDX facility on the SEM. The chemical constituents and stoichiometry of the prepared chromium oxide coatings were investigated by Raman spectroscopy and X-ray photoelectron spectroscopy. A Thermo Scientific DXR Raman spectroscopy and a Scienta ESCA 300 spectrophotometer equipped with a monochromatic $\mathrm{AlK} \alpha$ x-ray source were used for the Raman and XPS measurements respectively. The electrochemical studies were performed using a VoltaLab 40 PGZ301-potentiostat manufactured by Radiometer analytical, France; with the VoltaMaster-4 software used for data acquisition and analysis. The corrosion behaviour of the samples was studied in $0.5 \mathrm{M} \mathrm{NaCl}$ at a temperature range $25^{\circ} \mathrm{C}$ to $65^{\circ} \mathrm{C}$ using the EIS and cyclic polarisation techniques. The Volta lab 40 PGZ 301-potentiostat was connected to three electrodes electrochemical cell system, and the cell was placed in a temperature controlled water tub to maintain the temperature of the saline solution during the electrochemical test. Saturated calomel electrode (SCE), platinum wire and the prepared thin film surfaces were used as the reference, auxiliary and working electrodes respectively. The EIS tests were conducted at a frequency range of $100 \mathrm{mHz}$ to $40 \mathrm{KHz}$ with an AC amplitude of 
$20 \mathrm{mV}$. The semiconducting properties of the passive films formed on the surface of the samples were evaluated using the Mott-Schottky analysis. The samples were polarised from -1000 to $+1000 \mathrm{mV}$ vs SCE with a successive step of $50 \mathrm{mV}$.

\section{Results and Discussion}

\subsection{EDX and Raman spectroscopy}

The elemental composition and the oxide phase of the deposited chromium oxide coatings were evaluated using the EDX analysis and Raman spectroscopy. Figure 1a and Figure 1b show the EDX and Raman spectrum of chromium oxide coating deposited on glass substrates. The EDX spectrum (Figure 1a) shows the presence of chromium, oxygen and other elements such as silicon, calcium and magnesium from the glass slide. These peak positions are consistent with the EDX results that have been previously reported for the chromium oxide coatings $[8,10,15]$. The Raman spectrum (Figure 1b) reveals three Raman peaks that are associated with chromium (iii) oxide at $\sim 304 \mathrm{~cm}^{-1}, 350 \mathrm{~cm}^{-1}$, and $551 \mathrm{~cm}^{-1}$. The Raman peaks at $\sim 304 \mathrm{~cm}^{-1}$ and $350 \mathrm{~cm}^{-1}$ are attributed to the $E_{\mathrm{g}}$ symmetry of chromium oxide while the Raman peak at $550 \mathrm{~cm}^{-1}$ is related to the $A_{1 g}$ mode [7,10,16-18]. The presence of this particular phase of chromium oxide in the coating is desirable as this oxide phase is considered as the most chemically stable under ambient temperature among the chromium oxides $[7,10]$ and can possibly withstand a range of temperatures without degradation.
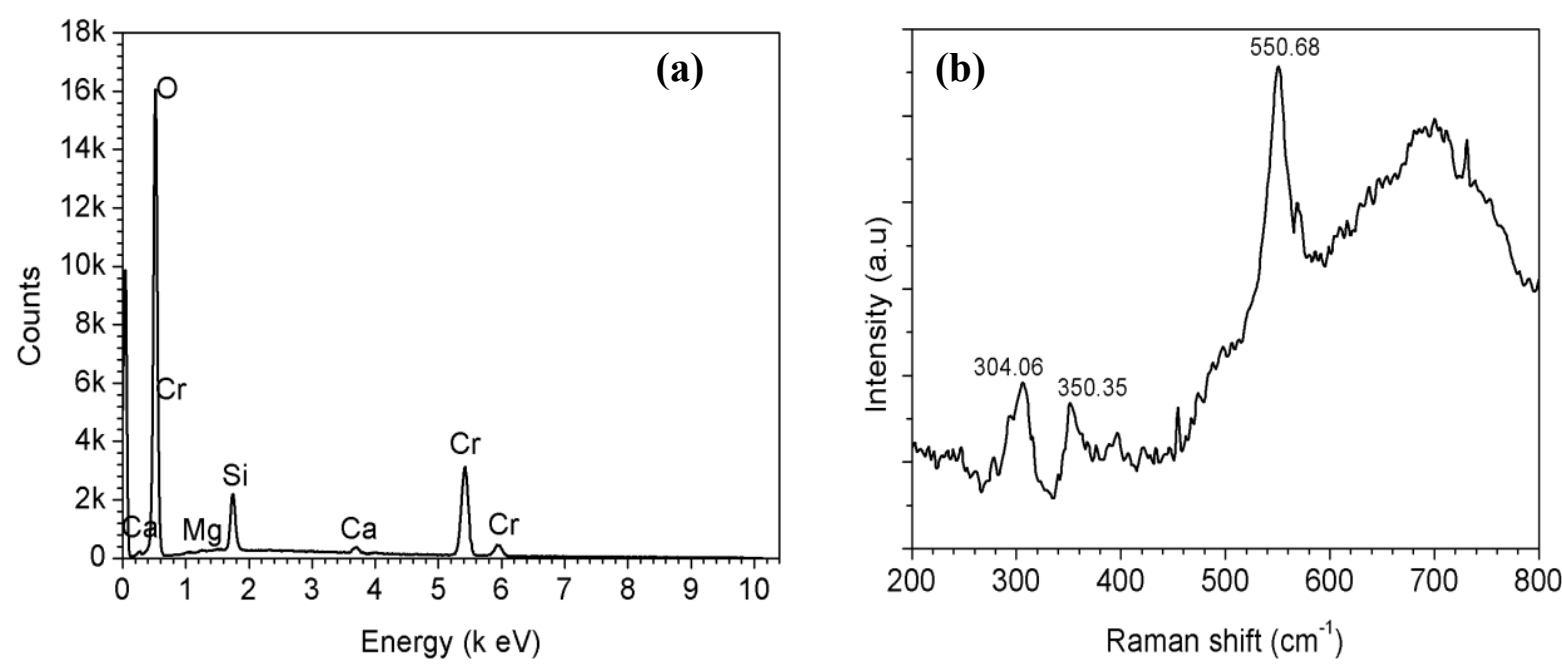

Figure 1: Chromium oxide coating prepared on a glass substrate at a deposition of 500W and at an oxygen flow rate of $10 \mathrm{sccm}$ (a) EDX spectrum (b) Raman spectrum. 


\subsection{X-ray photoelectron spectroscopy (XPS)}

The XPS investigation was used to further probe and confirm the chemical constituents and oxide phase of the deposited chromium oxide coating. The XPS spectra were taken at three different positions on the coated sample, and the plotted spectra are the representation of the average values. The obtained XPS data was analysed with CasaXPS software, Shirley method was used for the background subtraction, and the binding energy calibration was implemented by using the $\mathrm{C} 1 \mathrm{~S}$ peak taking it at $285 \mathrm{eV}$. The identification of the peaks present in the survey spectra was carried out with the help of the element library in CasaXPS software. The highresolution spectra obtained for $\mathrm{Cr} 2 \mathrm{P}$ doublet and $\mathrm{O} 1 \mathrm{~S}$ for the sample were curve fitted using a mixture of Gaussian and Lorentzian model.

The typical XPS spectra of the chromium oxide films prepared at a deposition power of $500 \mathrm{~W}$ and at an oxygen flow rate of $10 \mathrm{sccm}$ are presented in Figure 2. The peak of $\mathrm{C} 1 \mathrm{~S}, \mathrm{Cr} 2 \mathrm{P}$ and O1S in the survey scan spectra (Figure 2a) indicates the presence of carbon, chromium and oxygen in the sample. From the fitted Cr2P doublet (Figure 2b), five sub-peaks were created at binding energy position $575.25 \pm 0.2 \mathrm{eV}, 576.38 \pm 0.2 \mathrm{eV}, 578.46 \pm 0.2 \mathrm{eV}, 585.75 \pm 0.2 \mathrm{eV}$ and $587.49 \pm 0.2 \mathrm{eV}$. The peak at $575.25 \pm 0.2 \mathrm{eV}$ has been reported in the literature, and it relates to non-stoichiometric oxide phase between metallic chromium $574.9 \pm 0.2 \mathrm{eV}$ and chromium oxide at $576.38 \pm 0.2 \mathrm{eV}[19,20]$. The binding energy peak at $576.38 \pm 0.2 \mathrm{eV}$ is associated with $\mathrm{Cr}_{2} \mathrm{O}_{3}$ while the peak at $575.25 \pm 0.2 \mathrm{eV}$ is related to the existence of unreacted metallic chromium [7,21,22]. The O1S fitted spectrum (Figure 2c) showed B.E peaks at 530.84 $\pm 0.1 \mathrm{eV}$ and $529.78+0.1 \mathrm{eV}$ which is characteristic of oxygen in $\mathrm{Cr}_{2} \mathrm{O}_{3}$ phase and $\mathrm{Cr}(\mathrm{OH})_{3}$ respectively $[7,23,24]$. The XPS analysis results have complemented the quality of the prepared coating and further supported the observation made in the Raman spectroscopy investigations on the chemical state of the chromium oxide coatings. 

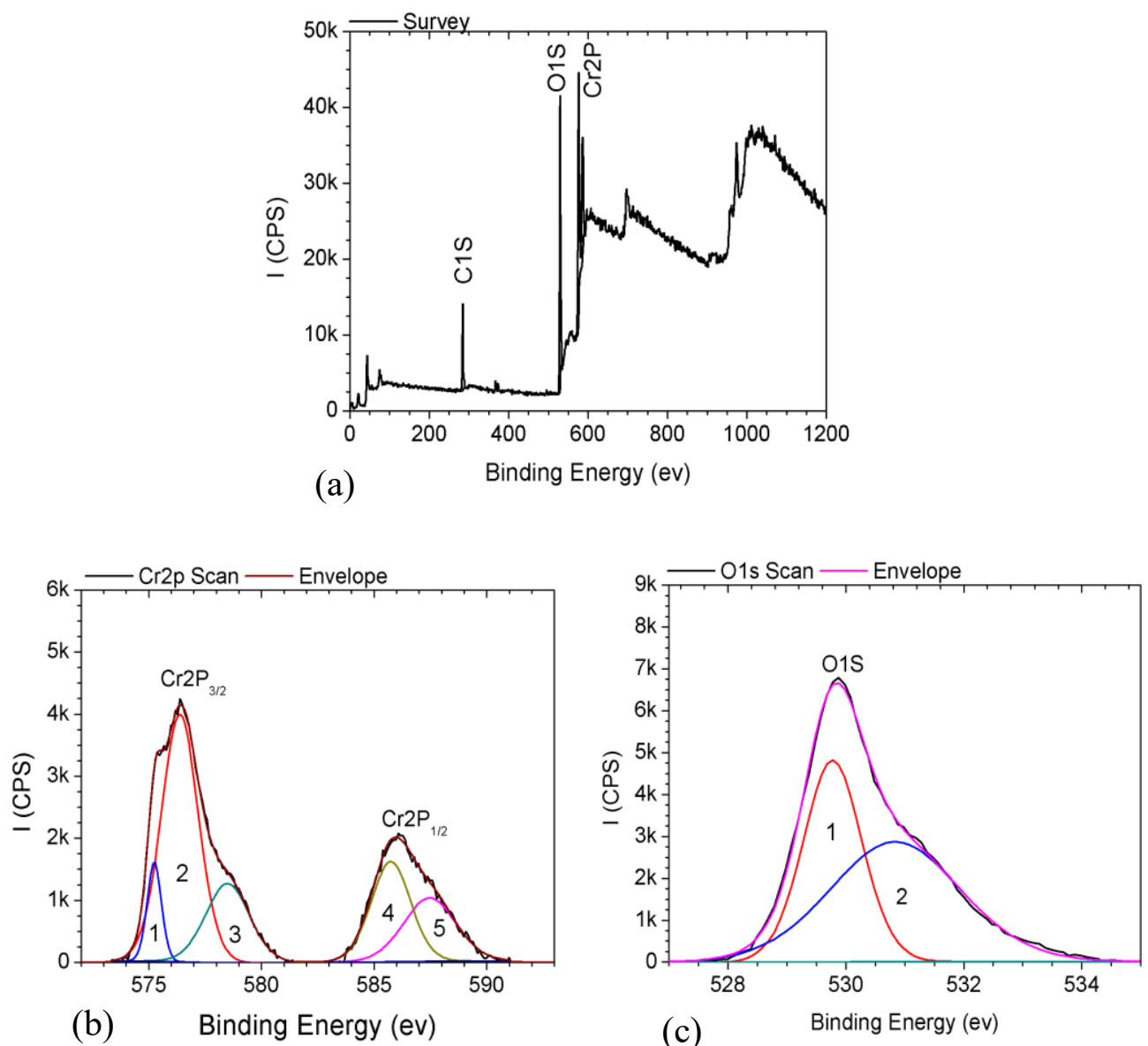

Figure 2: XPS scans for chromium oxide coating prepared on a glass substrate at a deposition power of $500 \mathrm{~W}$ and at an oxygen flow rate of $10 \mathrm{sccm}$; (a) Survey scan (b) $\mathrm{Cr} 2 \mathrm{P}$ doublet (c) O1S peak.

\subsection{SEM Analysis}

Figure 3 shows the tilted and cross-sectional views of the micrographs of the chromium oxide coating prepared on a glass substrate obtained using the scanning electron microscope (Hitachi S-4100 model). The SEM images reveal that the coating possesses a dense surface characterised by a mixture of columnar growth and layer-by-layer structure. The dense surface feature and granular structure can be beneficial in reducing or blocking the possible pathway through which aggressive ions such as chloride ions can penetrate through and attack the substrate material, thereby reducing the susceptibility of the coated substrate to localised corrosion and adhesion issues [10,12]. 

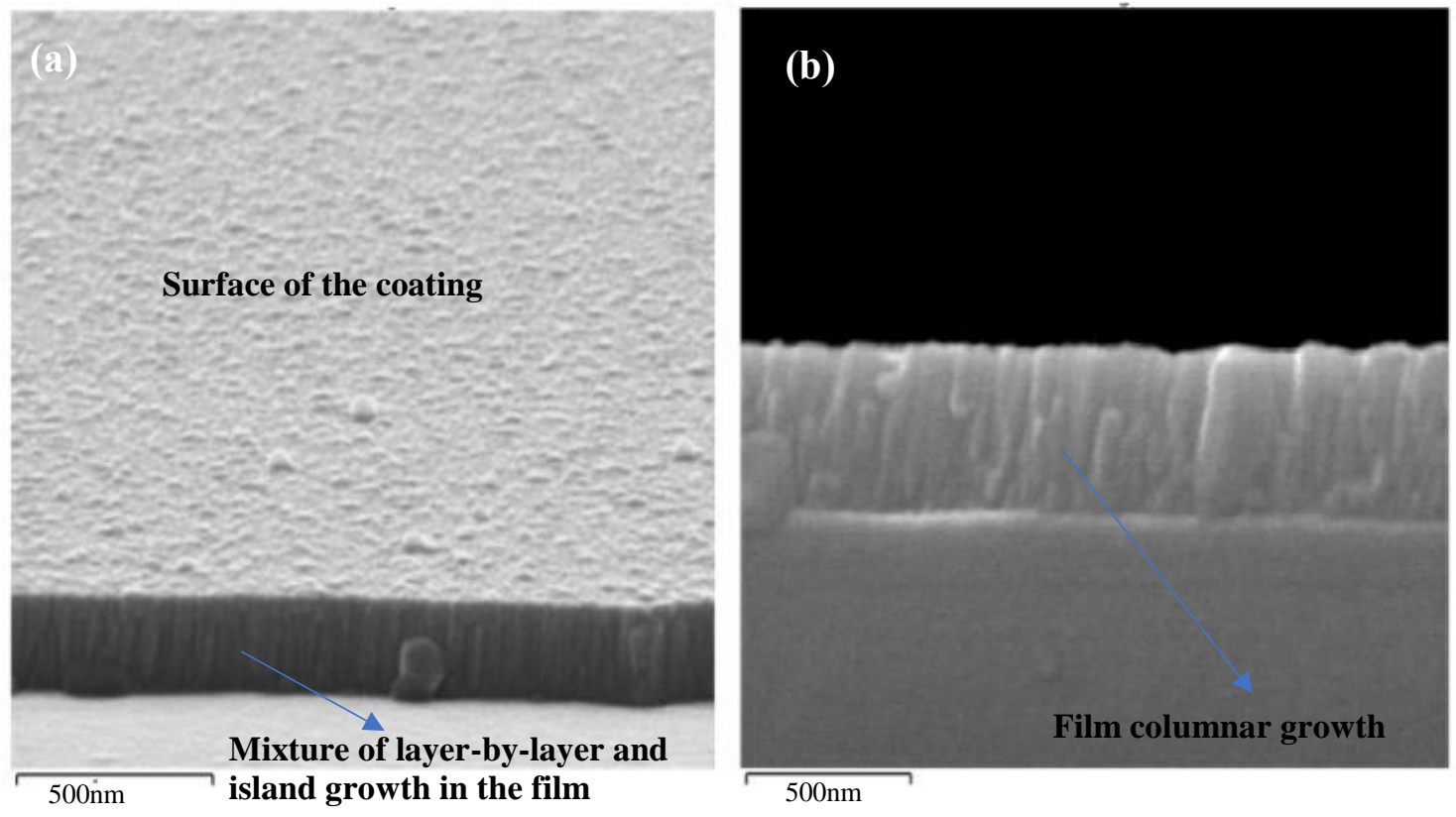

Figure 3: Typical SEM images of the chromium oxide coatings deposited on glass substrate (a) Tilted view (b) Cross-sectional view.

\subsection{Electrochemical Impedance Spectroscopy (EIS)}

The electrochemical impedance spectroscopy results obtained for chromium oxide coated samples in saline solution at a temperature range of $25^{\circ} \mathrm{C}$ to $65^{\circ} \mathrm{C}$ are presented as Nyquist plots and bode plots in Figures 4. The data obtained by EIS measurements were analysed by fitting them to an equivalent circuit model shown as an insert in Figure 4a using the Zview software. This equivalent circuit model has been used previously by various authors in literature to fit the EIS data of chromium oxide coatings tested in PBS and Ringers solutions $[12,13]$. The pure capacitance in the equivalent circuit model has been replaced by constant phase element (CPE) to account for the inhomogeneous state of the sample surfaces and also to improve the goodness of fitting [25-27]. The circuit element $R_{\mathrm{s}}$ represents the solution resistance, and $R_{\text {pore }}$ is the pore or coating resistance while $R_{p}$ is used to designate the polarisation resistance (ie charge transfer resistance). The constant phase elements CPE1 and CPE2 depict the electrolyte/coating interface capacitance and the coating/substrate interface capacitance respectively. The impedance of the constant CPE is given by [27-30]: 


$$
Z_{C P E}=\frac{1}{Q(j \omega)^{\alpha}}
$$

Where $\omega$ is the angular frequency ( $\mathrm{rad} / \mathrm{s}), Q$ is the CPE constant, $\alpha$ is the CPE exponent index, which represents the deviation of the capacitance of the passive film from the ideal behaviour. For pure capacitor $\alpha=1$ and for pure resistivity behaviour $\alpha=0$.

The value of the double layer capacitance $\left(\mathrm{C}_{d l}\right)$ was evaluated by Brug's equation as follow [31,32]:

$$
C_{d l}=Q^{\frac{1}{\alpha}}\left(R_{s}^{-1}+R_{t}^{-1}\right)^{\frac{\alpha-1}{\alpha}}
$$

Where $R_{s}$ is the solution resistance, $R_{t}$ is the charge transfer resistance.

Figure $3 \mathrm{a}$ and Figure $3 \mathrm{~b}$ show the influence of the electrolyte temperature variation on the electrochemical impedance response of the chromium oxide coatings tested in saline solution. The Nyquist spectra were found to decrease with an increase in the electrolyte temperature indicating a decrease in the corrosion resistance of the coating with the coating tested at $25^{\circ} \mathrm{C}$ showing the highest impedance response. This drop in corrosion performance with an increase in the electrolyte temperature is also evident in the bode plots where the spectra of the coatings tested at higher temperatures lied below those investigated at lower temperature condition. It is thought that an increase in electrolyte temperature leads to the formation of more defect in the passive films as revealed by the Mott-Schottky investigations and encouraged the diffusion of more corrosion species through the coatings. The corrosion parameters obtained from fitting the experimental data to the equivalent circuit are given in Table 2. It can be observed from Table 2 that the coating tested in saline solution at $25^{\circ} \mathrm{C}$ showed the maximum $R_{p}$ value of $2.40 \mathrm{M} \Omega . \mathrm{cm}^{2}$ which is an indication of higher polarisation resistance at the coating/substrate interface. This sample also possesses maximum $R_{\text {pore }}$ value of 123.90 $\mathrm{K} \Omega . \mathrm{cm}^{2}$ and the lowest double layer capacitance value of $33.3 \mu \mathrm{F} / \mathrm{cm}^{2}$ suggesting minimal penetration of chloride ions through the coating unto the coating/substrate interface when compared to the other samples. With an increase in the electrolyte temperature, the $R_{p}$ and $R_{\text {pore }}$ values were found to decrease while the CPE values (CPE-T) increased which means the degradation in the ability of the coating to protect the substrate from the corrosive environment due to the greater permeation of chloride ions from the solution [8]. Since an increase in the capacitance values is known to be related to an increase in the heterogeneity within the passive layer $[1,33]$, the observed increase in the CPE values with electrolyte temperature indicates 
that the passive oxide layer on the samples tested at higher temperatures presented more defect than the samples tested at a lower temperature. The decrease in the $R_{p}$ values as the electrolyte temperature increases gave rise to an increase in the double layer capacitance and a corresponding reduction in the overall electro-chemical impedance of the coated system. The coating investigated in saline solution at $65^{\circ} \mathrm{C}$ exhibited the least electrochemical impedance response characterised by a depressed semi-circle as well as the lowest $R_{p}$ and $R_{\text {pore }}$ values of $0.18 \mathrm{M} \Omega . \mathrm{cm}^{2}$ and $17.61 \mathrm{~K} \Omega . \mathrm{cm}^{2}$ respectively.
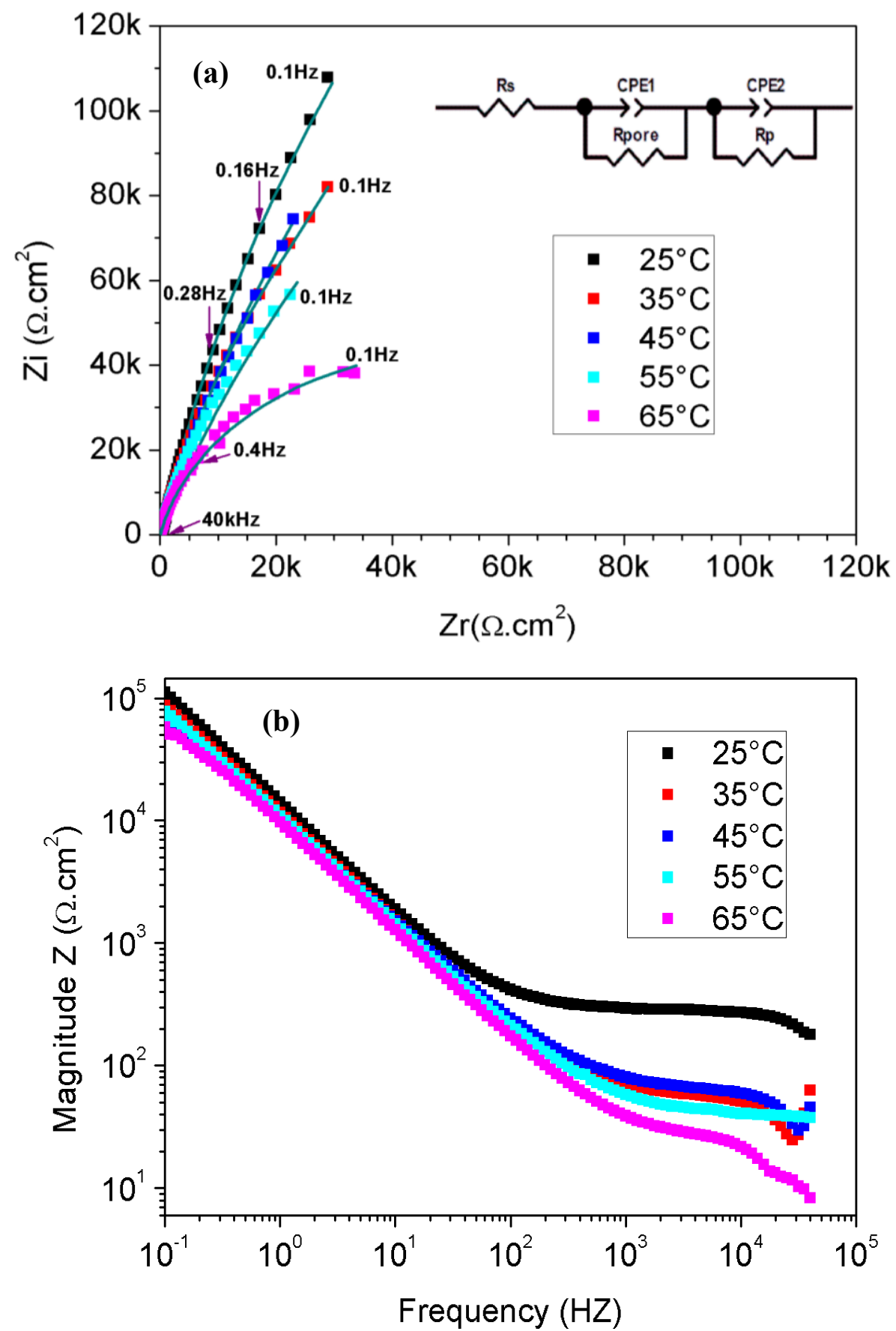

Figure 4: EIS plots of chromium oxide coatings deposited on stainless steel substrate at an oxygen flow rate of $10 \mathrm{sccm}$ and deposition power of $500 \mathrm{~W}$ and tested in saline solution at various temperatures (a) Nyquist plots (b) Bode plots. 
Table 2: EIS equivalent circuit parameters for chromium oxide coatings prepared at a deposition power of $500 \mathrm{~W}$, an oxygen flow rate of $10 \mathrm{sccm}$ and tested in saline solution at different temperatures

\begin{tabular}{|c|c|c|c|c|c|c|c|c|}
\hline Sample & $\begin{array}{c}\mathbf{R}_{\mathbf{s}} \\
\left(\Omega . \mathrm{cm}^{2}\right)\end{array}$ & $\begin{array}{c}\mathbf{C P E}_{\mathbf{1}}-\mathbf{T} \\
\left(\mathrm{cm}^{-2} \cdot \mathrm{S}^{-\mathrm{n}} \Omega\right)\end{array}$ & $\mathrm{CPE}_{1}-\mathrm{P}$ & $\begin{array}{c}\mathbf{R}_{\text {pore }} \\
\left(\mathrm{K} \Omega \cdot \mathrm{cm}^{2}\right)\end{array}$ & $\begin{array}{c}\mathbf{C P E}_{2}-\mathbf{T} \\
\left(\mathrm{cm}^{-2} \cdot \mathrm{S}^{-\mathrm{n}} \Omega\right)\end{array}$ & $\mathrm{CPE}_{2}-\mathrm{P}$ & $\begin{array}{c}C_{d l} \\
\left(\mu \mathrm{F} / \mathrm{cm}^{2}\right)\end{array}$ & $\begin{array}{c}\mathbf{R}_{\mathbf{p}} \\
\left(\mathrm{M} \Omega \cdot \mathrm{cm}^{2}\right)\end{array}$ \\
\hline $25^{\circ} \mathrm{C}$ & 21.43 & $1.41 \mathrm{E}-05$ & 0.84 & 123.90 & 7.94E-05 & 0.88 & 33.3 & 2.40 \\
\hline $35^{\circ} \mathrm{C}$ & 32.69 & $1.84 \mathrm{E}-05$ & 0.86 & 83.02 & $8.12 \mathrm{E}-05$ & 0.88 & 36.2 & 1.85 \\
\hline $45^{\circ} \mathrm{C}$ & 37.48 & $2.37 \mathrm{E}-05$ & 0.71 & 68.56 & $9.02 \mathrm{E}-05$ & 0.87 & 38.5 & 1.11 \\
\hline $55^{\circ} \mathrm{C}$ & 58.93 & $2.41 \mathrm{E}-05$ & 0.82 & 18.01 & $9.23 \mathrm{E}-05$ & 0.86 & 39.5 & 0.69 \\
\hline $65^{\circ} \mathrm{C}$ & 33.38 & $2.61 \mathrm{E}-05$ & 0.77 & 17.61 & $9.84 \mathrm{E}-05$ & 0.91 & 55.9 & 0.18 \\
\hline
\end{tabular}

\subsection{Cyclic polarisation}

The cyclic polarisation test was conducted to examine the susceptibility of the chromium oxide coated stainless steel substrates to localised corrosion in the saline solution at the temperature range of $25^{\circ} \mathrm{C}$ to $65^{\circ} \mathrm{C}$.

The coated samples on exposure to the saline solution, undergoes passivation process whereby some of the unreacted chromium on the sample (observed in the XPS) combines with oxygen to form stoichiometry of chromium oxide ( such as chromium (iii) oxide) and the reaction is given as :

$$
4 \mathrm{Cr}+3 \mathrm{O}_{2} \rightarrow 2 \mathrm{Cr}_{2} \mathrm{O}_{3}
$$

During the corrosion test, the basic anodic reactions occurring on the surface of the coated samples in the presence of chloride ions is expressed as [2]:

$$
\begin{gathered}
\mathrm{Cr} \rightarrow \mathrm{Cr}^{3+}+3 \mathrm{e}^{-} \\
\mathrm{Cr}_{2} \mathrm{O}_{3}+5 \mathrm{H}_{2} \mathrm{O} \rightarrow 2 \mathrm{CrO}_{4}{ }^{2-}+10 \mathrm{H}^{+}+6 \mathrm{e}^{-}
\end{gathered}
$$

Due to the process in equation (2) and (3), the passive film layer becomes thinner with an increase in the anodic potential leading to the gradual dissolution of the coating into metallic chromium ion.

The cathodic reaction, on the other hand, is given as [34]:

$$
\mathrm{O}_{2}+2 \mathrm{H}_{2} \mathrm{O}+4 \mathrm{e}^{-} \rightarrow 4 \mathrm{OH}^{-}
$$

The electrons generated at the anode are consumed at the cathode, and the progress of the electrode reactions/corrosion can be affected as a result of a restriction either in the rate of supply of reactants or the rate of removal of products of the electrode reaction. Antunes et al. 
[1] reported that the presence of the passive oxide layer with lower defect density could reduce the dissolution rate of the sample thereby retarding the corrosion rate of the material.

Figure 5 shows the cyclic polarisation test of the coating tested at various electrolyte temperatures. The coatings tested in the saline solution at $25^{\circ} \mathrm{C}$ and $35^{\circ} \mathrm{C}$ exhibited smaller hysteresis loop characterised with higher breakdown potentials (Table 3) when compared to coatings tested at $45^{\circ} \mathrm{C}, 55^{\circ} \mathrm{C}$ and $65^{\circ} \mathrm{C}$ suggesting their least susceptibility to localised corrosion. As can be seen from Table 3, the breakdown potential for all the samples lies in the range $349 \mathrm{mV}$ to $917 \mathrm{mV}$ vs SCE with the coated samples tested in saline at $25^{\circ} \mathrm{C}$ showing the highest breakdown potential $(917 \mathrm{mV})$. The superior resistance to pitting corrosion by the coatings tested at $25^{\circ} \mathrm{C}$ and $35^{\circ} \mathrm{C}$ in saline solution when compared to the other samples indicates the presence of less defective passive oxide film on the coatings as low defect density is associated with a higher localised corrosion resistance [1]. The finding is supported by the Mott-Schottky results where lower defect density was obtained in the passive layer for these samples. Furthermore, minimal corrosion current densities were observed for the samples tested in the saline solution at $25^{\circ} \mathrm{C}$ and $35^{\circ} \mathrm{C}$ when compared to other samples which can be attributed to the limited mobility of the chloride ions into the coatings. This resulted in a reduction in both the rate of the anodic and cathodic reaction as well as the observed smaller hysteresis loops. The highest current densities recorded for these samples were 0.185 and $0.273 \mathrm{~mA} / \mathrm{cm}^{2}$ and were one order of magnitude lower than those of the other coated samples tested at $45^{\circ} \mathrm{C}, 55^{\circ} \mathrm{C}$ and $65^{\circ} \mathrm{C}$ which was measured as 2.630, 3.265 and $4.825 \mathrm{~mA} / \mathrm{cm}^{2}$ respectively (Table 3 ). The $25^{\circ} \mathrm{C}$ and $35^{\circ} \mathrm{C}$ samples also exhibited higher protection potential values and as such can easily undergo oxide re-passivation process as follows [34]:

$$
2 \mathrm{Cr}+3 \mathrm{H}_{2} \mathrm{O} \rightarrow \mathrm{Cr}_{2} \mathrm{O}_{3}+6 \mathrm{H}^{+}+6 \mathrm{e}^{-}
$$

When the electrolyte temperature was increased to $35^{\circ} \mathrm{C}, 45^{\circ} \mathrm{C}, 55^{\circ} \mathrm{C}$ and $65^{\circ} \mathrm{C}$, the breakdown potential decreased progressively whereas the current density increased as illustrated in Figure 5 and Table 3. The huge change in the pitting corrosion parameters occurred when the temperature was raised to $45^{\circ} \mathrm{C}$. The initiation of higher acceptor defect densities in the passive layer due to an increase in temperatures provided more sites for ionic penetration through coatings unto the substrate leading to higher localised corrosion in the coated system. The lowest breakdown potential and highest current density were observed with the coated sample tested at $65^{\circ} \mathrm{C}$ indicating its susceptibility to pitting corrosion. This finding is supported by the 
earlier EIS and the proceeding Mott-Schottky analysis results where the sample showed the lowest impedance response and the highest acceptor defect density.

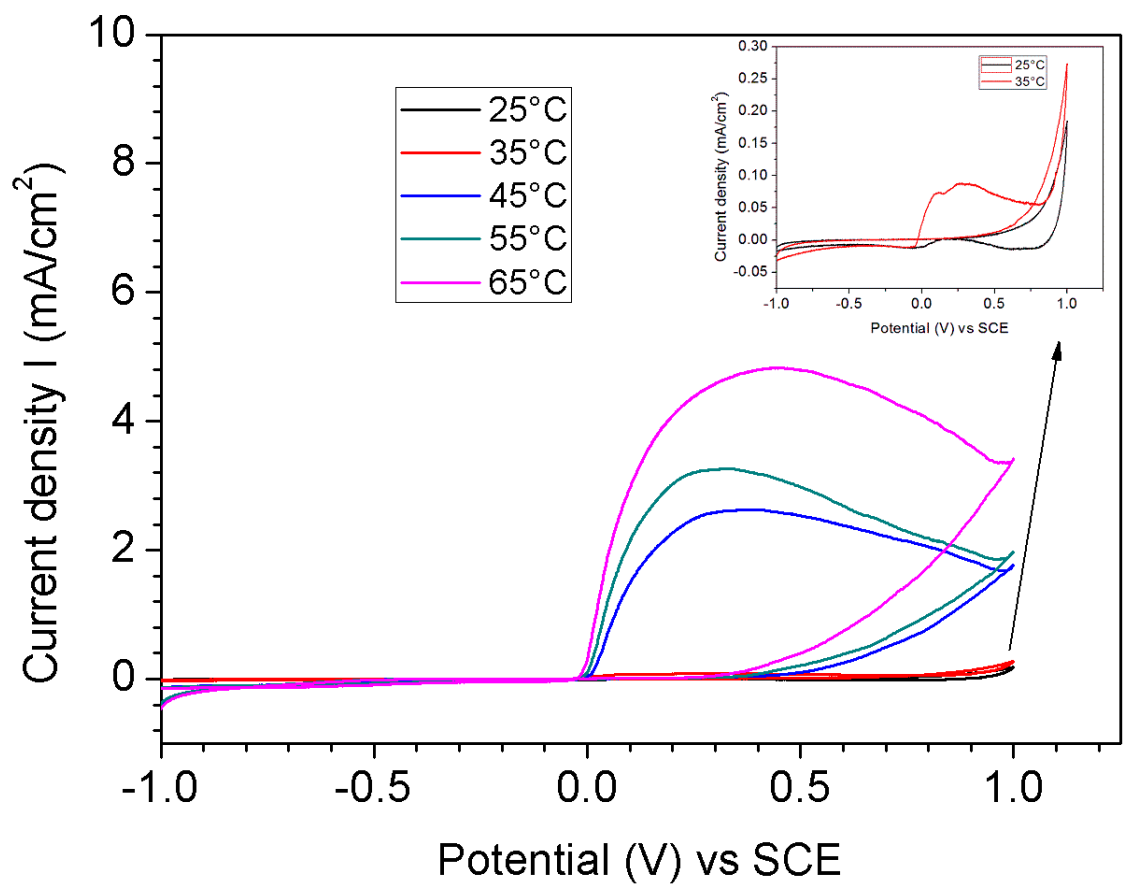

Figure 5: Cyclic polarisation plots of chromium oxide coatings deposited on stainless steel substrate at an oxygen flow rate of $10 \mathrm{sccm}$ and deposition power of $500 \mathrm{~W}$ and tested in saline solution at different temperatures.

Table 3: The corrosion parameters obtained from the cyclic polarisation analysis of the chromium oxide coatings tested at varying temperatures in saline solution.

\begin{tabular}{|c|c|c|}
\hline Sample & $\begin{array}{c}\text { Breakdown potential } \\
(\mathbf{m V})\end{array}$ & $\begin{array}{c}\text { Max. current density } \\
\left(\mathbf{m A} / \mathbf{c m}^{2}\right)\end{array}$ \\
\hline $\mathbf{2 5}^{\circ} \mathbf{C}$ & 917 & 0.185 \\
\hline $\mathbf{3 5}^{\circ} \mathbf{C}$ & 851 & 0.273 \\
\hline $\mathbf{4 5}^{\circ} \mathbf{C}$ & 496 & 2.630 \\
\hline $\mathbf{5 5}^{\circ} \mathbf{C}$ & 419 & 3.265 \\
\hline $\mathbf{6 5}^{\circ} \mathbf{C}$ & 349 & 4.825 \\
\hline
\end{tabular}

Figure 6 shows the SEM images of the prepared coating before and after pitting corrosion test in saline solution at a range of temperatures. The coated samples tested at $25^{\circ} \mathrm{C}$ and $35^{\circ} \mathrm{C}$ (Figure $6 \mathrm{~b}$ and Figure $6 \mathrm{c}$ ) showed no visible signs of pitting corrosion except the presence of crystallites from the saline solution on their surfaces. For the coatings tested at $45^{\circ} \mathrm{C}, 55^{\circ} \mathrm{C}$ and $65^{\circ} \mathrm{C}$ (Figure $6 \mathrm{~d}$ to Figure $6 \mathrm{f}$ ) signs of localised corrosion can be observed at different positions on the surface of the samples. The SEM images further highlight the better resistance to pitting corrosion for the samples tested at a temperature range of $25^{\circ} \mathrm{C}$ to $35^{\circ} \mathrm{C}$ when compared to the coatings tested at higher temperatures in the saline solution. 

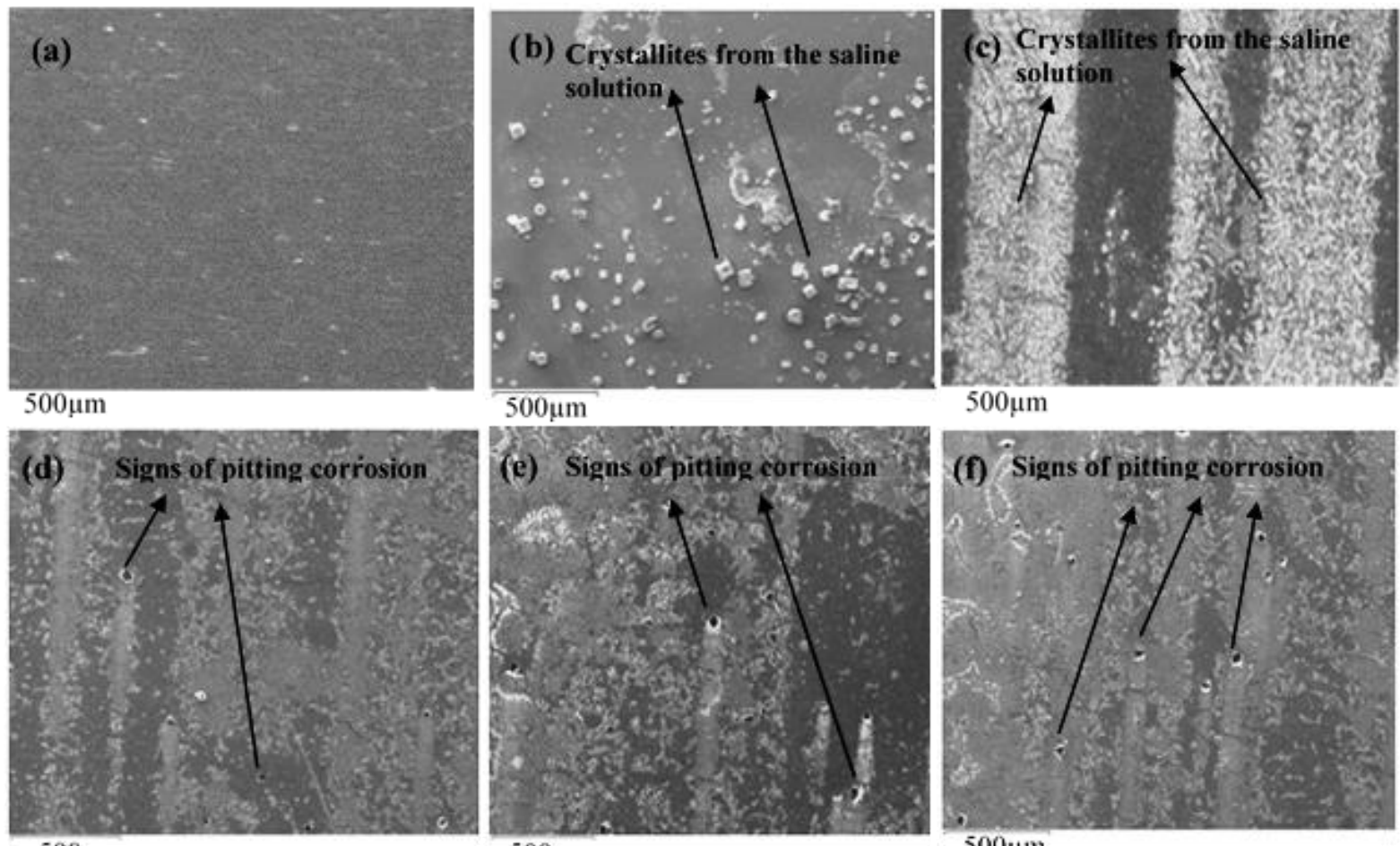

$500 \mu \mathrm{m}$

$500 \mu \mathrm{m}$

$500 \mu \mathrm{m}$

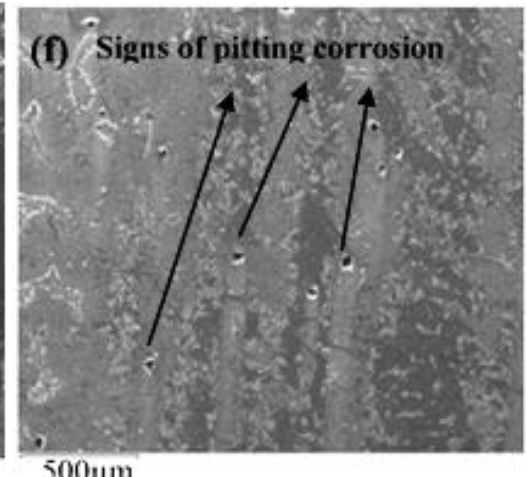

$500 \mu \mathrm{m}$

Figure 6: SEM images of the chromium oxide coatings (a) before corrosion test and after pitting corrosion test in saline solution at (b) $25^{\circ} \mathrm{C}$ (c) $35^{\circ} \mathrm{C}$ (d) $45^{\circ} \mathrm{C}$ (e) $55^{\circ} \mathrm{C}$ (f) $65^{\circ} \mathrm{C}$.

\subsection{Mott-Schottky Analysis}

The properties of passive films formed on the surface of the chromium oxide coated samples in saline solution at a temperature range of $25^{\circ} \mathrm{C}$ to $65^{\circ} \mathrm{C}$ were studied with the Mott-Schottky analysis. The equation relating the capacitance and the applied potential is given as [35-39]:

$$
\begin{aligned}
& C^{-2}=\frac{2}{\varepsilon \varepsilon_{o} Q N_{D}}\left(E-E_{F B}-\frac{K T}{Q}\right) \text {-for the n-type semiconductor } \\
& C^{-2}=-\frac{2}{\varepsilon \varepsilon_{o} Q N_{A}}\left(E-E_{F B}-\frac{K T}{Q}\right) \text {-for the p-type semiconductor }
\end{aligned}
$$

Where $\varepsilon_{o}$ is the permittivity of the free space $\left(8.85 \times 10^{-14} \mathrm{~F} / \mathrm{cm}\right), \varepsilon$ the dielectric constant of the passive film, Q the electron charge $\left(1.602 \times 10^{-19} C\right), N_{D}$ and $N_{A}\left(\mathrm{~cm}^{-3}\right)$ are the donor and acceptor densities respectively. $E_{F B}$ is the flat-band potential (V), $\mathrm{K}$ the Boltzmann constant $\left(1.38 \times 10^{-23} \mathrm{~J} / \mathrm{K}\right)$ and $\mathrm{T}$ is the absolute temperature $(\mathrm{K}) . N_{D}$ and $N_{A}$ can be determined from 
the slope of the experimental $C^{-2}$ versus applied potential (E), while the intercept on the potential axis corresponds to the flat-band potential $E_{F B}$. The validity of Mott-Schottky analysis is based on the assumption that the capacitance of the space charge layer is much smaller than the double layer capacitance.

The thickness (L) of films formed on the samples can be roughly calculated using the following expression $[1,40]$ :

$$
L=\frac{\varepsilon_{o} \varepsilon A}{C}
$$

Where $\mathrm{A}$ is the surface area of the sample, $\mathrm{C}$ is the capacitance of the oxide film. The other parameters were previously defined.

Figure 7 shows the Mott-Schottky plots of the chromium oxide coatings tested in saline solution at different electrolyte temperatures. The Mott-Schottky plots revealed a negative slope which is an indication that the passive films possess p-type semiconducting properties $[10,12,14]$. A similar observation has been reported for chromium oxide coatings tested in saline solution at ambient temperature and Ringer solution at $37^{\circ} \mathrm{C}[10,12]$. The slopes of the straight line of the plots were found to decrease with an increase in temperature which implies an increase in the acceptor point defect in the passive films on the surface of the coatings. The defect density was found to lie in the range $5.7021 \times 10^{19}$ to $1.5448 \times 10^{20} \mathrm{~cm}^{-3}$ with the coating tested at $65^{\circ} \mathrm{C}$ possessing the highest defect density as shown in Table 4.

With an increase in the electrolyte temperature, more defect sites were initiated in the passive films, and such sites acted as paths for fluid penetration unto the substrate thereby promoting the susceptibility of the material to localised corrosion. The presence of lower acceptor defect density in the coating tested at a lower temperature contributed significantly to the better corrosion resistance exhibited by the coating material [1]. Other factors such as enhanced diffusion of the corrosion species at higher temperatures can be associated with the observed reduction in the corrosion resistance of the coatings. These results are in agreement with the earlier EIS results and cyclic polarisation test where such variation was observed in the impedance response and pitting tendency of the coatings due to temperature change. 


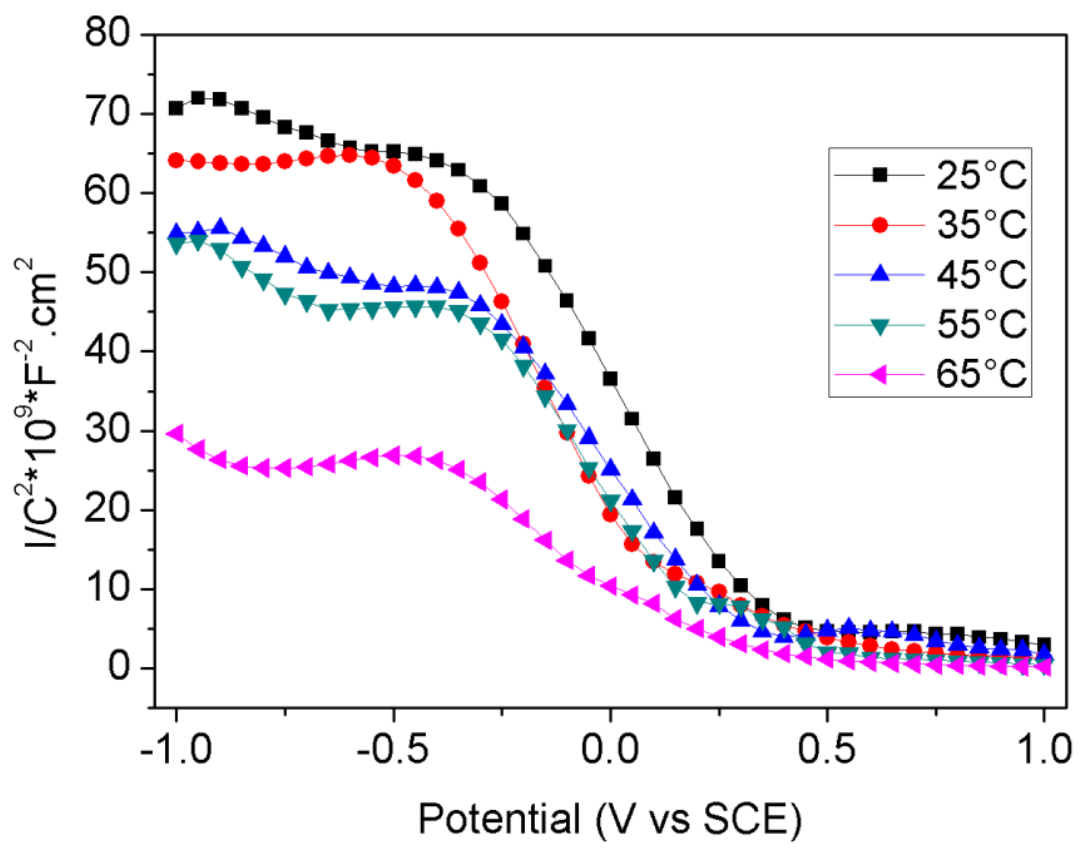

Figure 7: Mott-Schottky plots of chromium oxide coating deposited on stainless steel substrates at an oxygen flow rate of $10 \mathrm{sccm}$ and deposition power of $500 \mathrm{~W}$ and tested in saline solution at various temperatures.

Table 4: The defect densities obtained from the Mott-Schottky analysis of the chromium oxide coatings tested at varying temperatures in saline solution.

\begin{tabular}{|c|c|c|c|}
\hline Sample & Defect type & $\mathbf{N}\left(\mathbf{c m}^{-3}\right)$ & L $(\mathbf{n m})$ \\
\hline $\mathbf{2 5}^{\circ} \mathbf{C}$ & p-type & $5.7021 \times 10^{19}$ & 22.3 \\
\hline $\mathbf{3 5}^{\circ} \mathbf{C}$ & p-type & $6.3905 \times 10^{19}$ & 20.5 \\
\hline $\mathbf{4 5}^{\circ} \mathbf{C}$ & p-type & $6.9215 \times 10^{19}$ & 19.3 \\
\hline $\mathbf{5 5}^{\circ} \mathbf{C}$ & p-type & $7.6059 \times 10^{19}$ & 18.8 \\
\hline $\mathbf{6 5}^{\circ} \mathbf{C}$ & p-type & $1.5448 \times 10^{20}$ & 13.3 \\
\hline
\end{tabular}

A typical EDX spectrum of the coated sample (Figure 8) obtained after the Mott-Schottky test shows that the passive film is consist of chromium and oxygen alongside sodium and chloride ions from the saline solution. Other elements (such as nickel, carbon, and iron) observed in the spectrum comes from the stainless steel substrate. The thickness of the passive film layers was evaluated using equation 10 and was found to be in the range 13.3nm to $22.3 \mathrm{~nm}$ (Table 4). The layer formed on the coating tested at lower temperature was thicker than the ones formed on the samples tested at higher temperatures which most likely have also contributed to the variation in the corrosion resistance of the samples. The observed p-type semiconductor passive film is characterised by hole type defects and chromium vacancies as the dominate defects [41,42]. As the electrolyte temperature increases, an increasing partial dissolution of the passive film occurs, accompanied with enhanced diffusion of the corrosion species through the coatings [2] 
which result in a porous passive film with higher defect densities and lesser protective performance. This mechanism leads to an overall decrease in the corrosion resistance of the coated samples tested at a range of elevated temperatures.

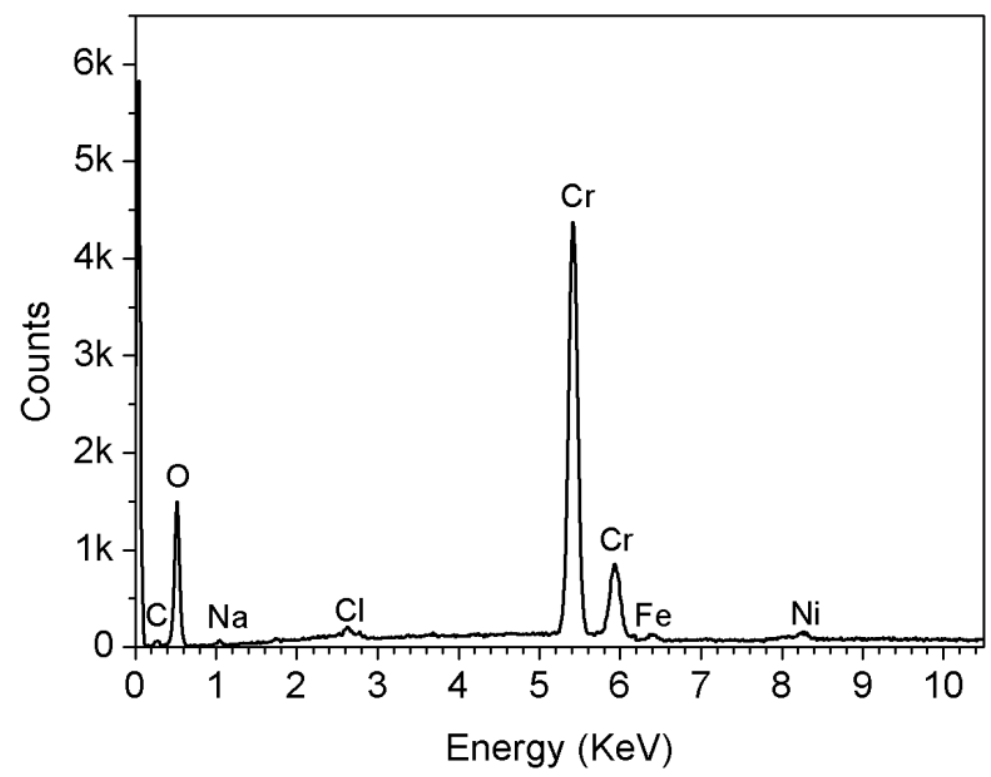

Figure 8: A typical EDX spectrum of the coated sample after Mott-Schottky test in saline solution at $45^{\circ} \mathrm{C}$.

The implication of the above corrosion results obtained using the EIS, cyclic polarisation and Mott-Schottky analysis is that these three corrosion monitoring methods can be used as complementary tools in probing the corrosion behaviour of coated stainless steel in aggressive environments such as saline solution. The obtained results were in good agreement, which suggests that the corrosion resistance of coated stainless steel can be associated with the integrity of the semiconducting properties of the passive films formed during immersion in saline under varying temperatures. It is, therefore, paramount that in the development of functional protective coating materials for stainless steel that attention should be given to the potential operating temperature of the coating as this parameter can initiate or facilitate the breakdown of the passive film formed on the coatings by creating defects in the passive film and enhancing the diffusion of corrosion species into the coatings. Our future work will involve depositing thin films with epitaxial growth as an interlayer between the chromium oxide coatings and the stainless steel substrate to help enhance the pitting corrosion resistance of the coating at a temperature of $45^{\circ} \mathrm{C}$ and beyond. 


\section{Conclusion}

The corrosion behaviour and semiconducting properties of chromium oxide coatings deposited by RF magnetron sputtering have been investigated in saline solution at a temperature range of $25^{\circ} \mathrm{C}$ to $65^{\circ} \mathrm{C}$. The elemental composition and oxide phase of the prepared coating was confirmed with the EDX, Raman spectroscopy and XPS. The coating was found to be mainly chromium (iii) oxide phase based on the $\mathrm{E}_{\mathrm{g}}$ and $\mathrm{A}_{1 \mathrm{~g}}$ symmetry modes observed in the Raman spectrum. The electrochemical test showed variation in the electrochemical impedance response and acceptor defect density of the coating characterised by the p-type semiconducting passive film. The corrosion resistance of the coatings was found to decrease with an increase in the electrolyte temperature, and this can be attributed to the increase in the acceptor defect density in the passive film on the coatings as observed in the Mott-Schottky analysis and enhanced diffusion at higher temperatures. With an increase in the solution temperature, passive films with higher defects were formed on the samples. The EIS and Mott-Schottky results show that the passive protective film formed on the surface of the coatings can be compromised due to elevated temperature leading to the reduced corrosion resistance of the coating material. The cyclic polarisation test revealed a pronounced increase in the current density and hysteresis loop as well as a decrease in the breakdown potential when the electrolyte temperature was raised to the temperature range $45^{\circ} \mathrm{C}$ to $65^{\circ} \mathrm{C}$. This change in the corrosion parameters indicates higher susceptibility of the coating to localised corrosion at the above-mentioned temperature range. This information is necessary for potential application areas such as marine environment and desalination plants where the coating will be in contact with chloride solution at elevated or range of temperatures.

\section{Competing interests}

We declare we have no competing interests

\section{Funding}

We received no funding for this study. 


\section{References}

[1] Antunes R A, De Oliveira M C L and Costa I 2012 Study of the correlation between corrosion resistance and semi-conducting properties of the passive film of AISI 316L stainless steel in physiological solution Mater. Corros. 63 586-92

[2] Wang L N, Shinbine A and Luo J L 2013 Electrochemical behavior of CoCrMo implant in Ringer's solution Surf. Interface Anal. 45 1323-8

[3] Li D, Chen D, Wang J and Chen H 2010 Chemical composition and Mott-Schottky analysis of passive film formed on G3 alloy in bicarbonate/carbonate buffer solution Acta Metall. Sin. (English Lett. 23 461-72

[4] Hanawa T 2004 Metal ion release from metal implants Mater. Sci. Eng. C 24 745-52

[5] Matusiewicz H 2014 Acta Biomaterialia Potential release of in vivo trace metals from metallic medical implants in the human body: From ions to nanoparticles - A systematic analytical review 10 2379-403

[6] Kong D S, Chen S H, Wang C and Yang W W 2003 A study of the passive films on chromium by capacitance measurement Corros. Sci. 45 747-58

[7] Barshilia H C and Rajam K S 2008 Growth and characterization of chromium oxide coatings prepared by pulsed-direct current reactive unbalanced magnetron sputtering Appl. Surf. Sci. 255 2925-31

[8] Liu H, Tao J, Xu J, Chen Z and Gao Q 2009 Corrosion and tribological behaviors of chromium oxide coatings prepared by the glow-discharge plasma technique Surf. Coatings Technol. 204 28-36

[9] Monticelli C, Balbo A and Zucchi F 2011 Corrosion and tribocorrosion behaviour of thermally sprayed ceramic coatings on steel Surf. Coatings Technol. 205 3683-91

[10] Ogwu A A, Oje A M and Kavanagh J 2016 Corrosion, ion release and Mott-Schottky probe of chromium oxide coatings in saline solution with potential for orthopaedic implant applications Mater. Res. Express 345401

[11] Oje A M, Ogwu A A, Kavanagh J, Gibson D and Mirzaeian M 2015 The Effect of Growth Conditions on the Surface Energy, Optical Properties and Saline Corrosion Resistance of Amorphous Chromium Oxide Thin Films Prepared by Reactive Magnetron Sputtering 58th Annual Technical Conference Proceedings, Santa Clara, CA April 25-30, 2015 ISSN 0737-5921 1 pp 1-7

[12] Oje A M and Ogwu A A 2017 Chromium oxide coatings with the potential for eliminating the risk of chromium ion release in orthopaedic implants $R$. Soc. Open Sci. 4170218

[13] Swaminathan V, Zeng H, Lawrynowicz D, Zhang Z and Gilbert J L 2011 Electrochemical investigation of chromium oxide coated Ti-6Al-4V and Co-Cr-Mo alloy substrates J. Biomed. Mater. Res. BApplied Biomater. 98B 369-78

[14] Goodlet G, Faty S, Cardoso S, Freitas P P, Simoes A M P, Ferreira M G S and Da Cunha Belo M 2004 The electronic properties of sputtered chromium and iron oxide films Corros. Sci. 46 1479-99

[15] Abdullah M M, Rajab F M and Al-Abbas S M 2014 Structural and optical characterization of $\mathrm{Cr} 2 \mathrm{O} 3$ nanostructures: Evaluation of its dielectric properties AIP Adv. 4

[16] Sousa P M, Silvestre A J, Popovici N and Conde O 2005 Morphological and structural characterization of CrO2/Cr2O3 films grown by Laser-CVD Appl. Surf. Sci. 247 4238

[17] Mougin J, Bihan T Le and Lucazeau G 2001 High-pressure study of Cr 2 O 3 obtained by high-temperature oxidation by X-ray diffraction and Raman spectroscopy J. Phys.

Chem. ... 62 553-63 
[18] Khamlich S, Manikandan E, Ngom B D, Sithole J, Nemraoui O, Zorkani I, McCrindle $\mathrm{R}$, Cingo N and Maaza M 2011 Synthesis, characterization, and growth mechanism of a-Cr2O3 monodispersed particles J. Phys. Chem. Solids 72 714-8

[19] Chen Y, Ding K, Yang L, Xie B, Song F, Wan J, Wang G and Han M 2008 Nanoscale ferromagnetic chromium oxide film from gas-phase nanocluster deposition Appl. Phys. Lett. 92173112

[20] Wang Z, Xi L, Yang Y, Li Y, Han X, Zuo Y and Wang J 2014 Spin-dependent Transport Properties of CrO2 Micro Rod Nano-Micro Lett. 6 365-71

[21] Aronniemi M, Sainio J and Lahtinen J 2005 Chemical state quantification of iron and chromium oxides using XPS: The effect of the background subtraction method Surf. Sci. 578 108-23

[22] Bhushan B, Theunissen G S A M and Li X D 1997 Tribological studies of chromium oxide films for magnetic recording applications Thin Solid Films 311 67-80

[23] Maurice V, Cadot S and Marcus P 2000 XPS , LEED and STM study of thin oxide films formed on Cr ( 110 ) Surf. Sci. 458 195-215

[24] Biesinger M C, Brown C, Mycroft J R, Davidson R D and McIntyre N S 2004 X-ray photoelectron spectroscopy studies of chromium compounds Surf. Interface Anal. 36 1550-63

[25] Grips V K W, Ezhil Selvi V, Barshilia H C and Rajam K S 2006 Effect of electroless nickel interlayer on the electrochemical behavior of single layer $\mathrm{CrN}$, TiN, TiAlN coatings and nanolayered TiAlN/CrN multilayer coatings prepared by reactive dc magnetron sputtering Electrochim. Acta 51 3461-8

[26] Liu C, Bi Q, Leyland A and Matthews A 2003 An electrochemical impedance spectroscopy study of the corrosion behaviour of PVD coated steels in $0.5 \mathrm{~N} \mathrm{NaCl}$ aqueous solution: Part I.: EIS interpretation of corrosion behaviour Corros. Sci. 45 1243-56

[27] Musa A Y, Mohamad A B, Kadhum A H A and Takriff M S 2012 Corrosion inhibition of mild steel in $1.0 \mathrm{M} \mathrm{HCl}$ by amino compound: Electrochemical and DFT studies Metall. Mater. Trans. A Phys. Metall. Mater. Sci. 43 3379-86

[28] De Assis S L, Wolynec S and Costa I 2006 Corrosion characterization of titanium alloys by electrochemical techniques Electrochim. Acta 51 1815-9

[29] Lavos-Valereto I C, Wolynec S, Ramires I, Guastaldi A C and Costa I 2004 Electrochemical impedance spectroscopy characterization of passive film formed on implant Ti-6Al-7Nb alloy in Hank's solution J. Mater. Sci. Mater. Med. 15 55-9

[30] Hsu C H and Mansfeld F 2001 Concernng the conversion of the constant phase element parameter Y0 into a capacitance Corrosion 57 747-8

[31] G.J. Brug, A.L.G. van den Eaden, M. Sluyters-Rehbach J H S 1984 The analysis of electrode impedances complicated by the presence of a constant Phase Element $J$. Electroanal. Chem. 176, 275

[32] Duvall M, Ayagou D, Tuyet T, Tran M, Tribollet B, Kittel J, Sutter E, Ferrando N, Mendibide C and Duret-thual C 2018 Electrochemical impedance spectroscopy of iron corrosion in H2S solutions Electrochim. Acta 282 775-83

[33] Yashiro H, Pound B, Kumagai N and Tanno K 1998 The effect of permeated hydrogen on the pitting of type 304 stainless steel Corros. Sci. 40 781-91

[34] Liu Y and Chen B 2018 In vivo corrosion of CoCrMo alloy and biological responses: a review Mater. Technol. 33 127-34

[35] Li H, Jiang Z, Feng H, Wang Q, Zhang W, Fan G and Li G 2015 Electrochemical Corrosion Characteristics of Super Duplex Stainless Steel S32750 in LT-MED Environment Int. J. Electrochem. Sci. 10 1616-31

[36] Hakiki N E, Montemor M F, Ferreira M G S and da Cunha Belo M 2000

Semiconducting properties of thermally grown oxide films on AISI 304 stainless steel 
Corros. Sci. 42 687-702

[37] Hakiki N B, Boudin S, Rondot B and Da Cunha Belo M 1995 The electronic structure of passive films formed on stainless steels Corros. Sci. 37 1809-22

[38] Ferreira M G S, Da Cunha Belo M, Hakiki N E, Goodlet G, Montemor M F and Simõesa A M P 2002 Semiconducting properties of oxide and passive films formed on AISI 304 stainless steel and Alloy 600 J. Braz. Chem. Soc. $13433-40$

[39] Ferreira M G S, Hakiki N E, Goodlet G, Faty S, Simoes A M P and Belo M D 2001 Influence of the temperature of film formation on the electronic structure of oxide films formed on 304 stainless steel Electrochim. Acta 46 3767-76

[40] Sikora E, Sikora J and Macdonald D D 1996 A new method for estimating the diffusivities of vacancies in passive films Electrochim. Acta 41 783-9

[41] de Oliveira M C L, Pereira V S M, Correa O V, de Lima N B and Antunes R A 2013 Correlation between the corrosion resistance and the semiconducting properties of the oxide film formed on AZ91D alloy after solution treatment Corros. Sci. 69 311-21

[42] Ibáñez-Ferrándiz M, García-García D M, Bakour S, Garcia-Anton J, Blasco-Tamarit E and Guenbour A 2010 Effect of Temperature on the Corrosion Resistance of Stainless Steels in Polluted Phosphoric Acid 10 49-61 